\title{
HIV detection in a blood donor: importance of serological screening
}

\begin{abstract}
We report the case of a first time blood donor in which the presence of HIV antigen/ antibody in absence of HIV ribonucleic acid was detected. The male donor was attended in the Hemotherapy Unit of our institution in the City of Buenos Aires. During the pre-donation interview he didn't mention any risky situation that could be a motive of deferral nor did he exclude himself after it. Given the laboratory's results, we could find ourselves facing a person that could be receiving antiretroviral therapy for HIV or to the group of those infected by HIV named "elite controllers" whose immune system allows them to remain asymptomatic during long periods of time. We couldn't corroborate these possibilities since he didn't respond to our summons. Cases like this one confirm the importance of the use of serologic screening tests for the detection of antigens and antibodies as well as the detection of nucleic acids for HIV.
\end{abstract}

Volume 3 Issue | - 2016

\author{
Tabares M, Macadam C,Alvarez A, Chaves A
} Hemotherapy Unit, Hospital General de Agudos, Argentina

Correspondence: Maria Tabares, Hemotherapy Unit, HGA "I.Pirovano", Monroe 3555, CP 1430, CABA, Argentina, Tel 549 II 45427623, Email pinitabares@gmail.com

Received: August 23, 2016 | Published: November 17, 2016

Keywords: elite controllers, serological screening, blood donor, hemotherapy

Abbreviations: HIV, human immunodeficiency virus; HTLV, human T-lymphotropic virus; $\mathrm{HBV}$, hepatitis B virus; $\mathrm{HCV}$, hepatitis $\mathrm{C}$ virus; NAT, nucleic acid testing; RNA, ribonucleic acid; DNA, deoxyribonucleic acid; Ag, antigen; Ab, antibody; AIDS, acquired immune deficiency syndrome; LTNP, long term non progressor; HAART, highly active antiretroviral therapy

\section{Introduction}

In Argentina, The National Blood Law 22.990 establishes the obligation to use serologic tests to detect transfusion-transmitted diseases such as HIV, HTLV, HBV, HCV, Chagas, Syphilis and Brucellosis ${ }^{1}$ NAT techniques are being performed since August 2013 in all the blood banks at hospitals belonging to the Hemotherapy Network of the Government of the City of Buenos Aires. The donor's samples are sent to the Pediatric Hospital "Profesor Dr. Juan P. Garrahan", a Hemotherapy Regional Centre, of which we are users.

The detection of viral nucleic acids by means of NAT tests which are mandatory in Hemotherapy Centers worldwide, has shortened the window phase and reduced the residual risk of acquiring a viral infection after the transfusion of haemo components. The techniques designed for blood banks for the detection of nucleic acids (qualitative), allow the detection of RNA from HCV 4-5days after the infection, RNA from HIV in 5-6 days and DNA from HBV in 2530 days. $^{2}$ In HIV infections we can obtain discordant results between serologic screening tests and NAT in the same sample. This evidences the importance of doing both tests so as to ensure transfusional safety. We now present the case of a blood donor in which the laboratory tests were repeatedly positive for HIV (antigen and antibody) both in the serum and plasma samples and negative for nucleic acids.

\section{Case description}

A 32years old male, first time donor for blood replenishment attended the blood bank of our Institution. The serologic results were repeatedly reactive for HIV Antigen-Antibody using the following screening methods: Architect HIV Ag/Ab Abbott Combo assay (chemiluminescense) and Serodia-HIV (gelatin particle agglutination) test for antibodies to HIV-1 in both serum and plasma. The donor sample was sent to Garrahan Hospital where the viral screening was carried out. The result of NAT for HIV (cobas ${ }^{\circledR}$ TaqScreen. MPX 2.0 Roche Test, diagnostics for HIV-HCV-HBV) was negative. It was first performed in a pool of six samples and the result was then verified with an individual sample of the plasma unit.

The Viral load was performed on the plasma unit, resulting undetectable $(<50$ copies $/ \mathrm{ml})$ and a Western Blot which resulted positive. Both determinations were performed at the Garrahan Hospital, Regional Hemotherapy Centre. As regards to the predonation interview and the clinical examination, the donor did not refer risk situations which could produce deferral. He neither excluded himself after the blood donation. The donor was summoned three times by telephonic telegram and even by telephone and in no case responded to the summons.

\section{Discussion}

The natural history about HIV infection without any interventions with medications allows three different stages:

i. primary acute infection

ii. clinical latency period or chronic infection phase and

iii. symptomatic AIDS phase

The primary infection period or primo-infection is characterized by an active viral replication, as well as an arousal of a specific immunological response against HIV-1 and the viremial control. This acute infection can extend itself from four to eight weeks, covering two stages. A first viral dissemination stage which culminates with the viremial peak during the first days after the infection, the virus is reproduced in great quantities by the lymphocytes, activated in the lymphatic nodules and is set free into the blood. The titles encountered can be above 5,000 infectious particles or $10^{7}$ molecules of viral RNA per $\mathrm{ml}$ of plasma. During this period no specific antibodies against HIV-1 are detected and are hence termed window phase. During the first weeks, a transitory decline in the absolute number of $\mathrm{T} \mathrm{CD}^{+}$ 
lymphocytes in peripheral blood can be observed and high levels of plasmatic viral load. The second stage is characterized by the sudden viremial reduction which would correspond to the partial elimination of the virus in the blood concomitantly with the detection of specific antibodies against the virus that is with the seroconversion period accompanied by an increase in $\mathrm{T} \mathrm{CD} 4^{+}$lymphocytes.

Figure 1 illustrates the typical course of the HIV-1 infection. During the primary infection, $50 \%$ of the infected persons can show clinical symptoms which resemble an infectious mononucleosis which if extended, can be associated with an unfavorable forecast. The viral degree in this step is a direct predictor of the progressive speed of the disease. The specific humoral response appears between two weeks and three months after the infection. After the seroconversion, a period of clinical latency befalls, or chronic phase, which precedes the initiation of the disease and can vary between one to fifteen or more years. During all this period the infected person remains free from symptoms and AIDS signs. Nevertheless, the course of the infection continues in an inadvertent manner and a series of virological and immunological phenomena occur accompanied by a gradual and inexorable deterioration of the immune system. The viral propagation is suppressed by the action of the T cytotoxic lymphocytes; the viral population becomes more heterogeneous owing to the continuous selection of specific mutations which are due to the pressure of the immune response. A slow and progressive reduction of the absolute number of $\mathrm{T} \mathrm{CD} 4^{+}$lymphocytes begins, which generally persists during several years.

The final steps of the disease are characterized by the presence of a severe immune suppression with a very low count of T CD4+ lymphocytes (less than 200/ml) and high levels of plasmatic viremia. A decrease of the total amount of $\mathrm{T}$ cytotoxic $\mathrm{CD} 8^{+}$lymphocytes is observed. In the lymphatic nodules, the viral replication increases with the consequent destruction of the lymphoid cells. The viral population becomes relatively homogeneous. As a result of the immune suppression, opportunist infections ensue, which finally lead to the patient's death ${ }^{3}$ (Figure 1).

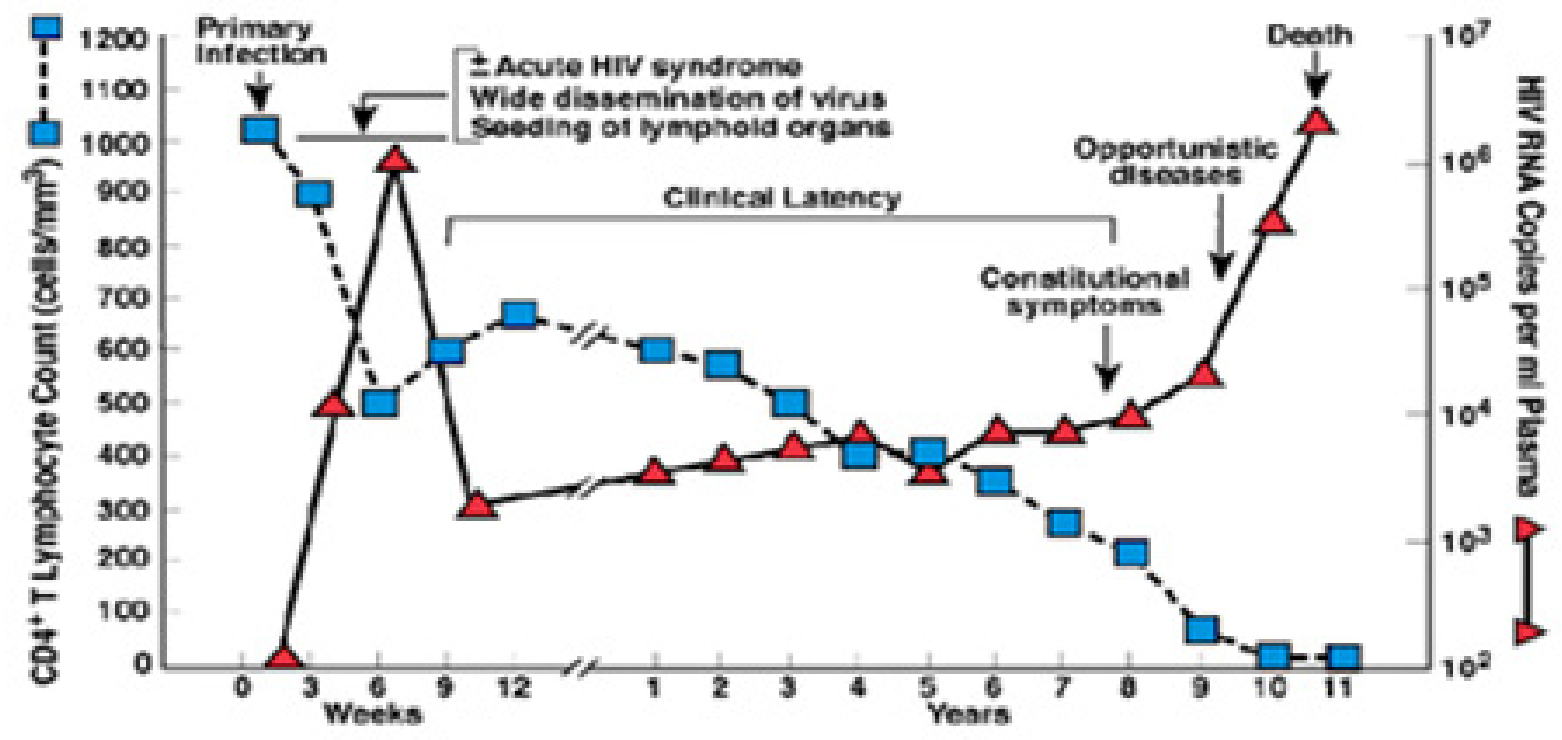

Modined From: Favel, A. S, et at Ann. fotem, Med, 124:054, 1990

Figure I Typical course of HIV infection that shows the relationship between the levels of HIV (viral load) and CD4 ${ }^{+}$T cell counts over the average course of untreated HIV infection.

From the outbreak of the epidemic caused by HIV it is noted that under a repetitive viral exposition there are individuals that are not infected, indicating an evident natural protection. For example, children who are not infected, born from HIV seropositive mothers or individuals repeatedly exposed to HIV via HIV-seropositive couples. Furthermore, in HIV-infected people there is a great individual variability as to the morbid-mortality of the infection. Some infected patients develop AIDS very rapidly, and are named prompt progressors. Other HIV-1 seropositive patients remain asymptomatic during over a decade without antiretroviral treatment, named LTNP (long term non progressors), either because they maintain CD4 lymphocyte count $>500 \mathrm{~mm}^{3}$ after seven or eight years of HIV-1 infection, or because they spontaneously control their viremia, commonly denominated "elite controllers", that in a $90 \%$ of cases have their RNA HIV plasmatic values $<50$ copies $/ \mathrm{ml}$. The bibliography also defines HIV controllers when in the $90 \%$ of the cases their plasmatic viral loads are $<500$ copies $/ \mathrm{ml}$ over a lapse greater than twelve months. Unusual cases $(<1 \%$ of all infected individuals) show both characteristics of long term non progressors and elite controllers and are denominated long term elite non progressors. ${ }^{4,5}$

Some authors interpret that elite controllers reach medical services mostly because of specific situations rather than for health questions, for example, when their couples are traditional HIV positive persons or when they constantly maintain sexual intercourse without condoms and are subject to routine tests to know if they have the infection. The emergence of the Highly Active Antiretroviral Therapy (HAART) in 1996 has modified the natural history of the infection by the virus of acquired Immunodeficiency. Cohort studies of infected persons during the period before HAART showed that the time elapsed until the development of AIDS was in most cases from one to ten years.

The combined HAART have established a substantial improvement in the quality of the infected individuals as well as a reduction of the morbid-mortality associated to the HIV infection. The combined use of drugs aims at achieving an augmented inhibitive effect against the HIV replication. The success of the treatment can be monitored 
with immunological studies (CD4+ counts) and viral (plasmatic viral load). It is intended that the patient with two or three months of treatment may have his viral load undetectable $(<50$ copies $/ \mathrm{ml}){ }^{6,7}$ In clinically healthy donors there is a chance of finding reactive tests for antibodies/antigens and NAT that would be the case of a person infected with HIV. In the case that they were in a window phase, non reactive antibodies would be present, with reactive NAT. And if it were to concern infected individuals under treatment or those infected and capable of controlling the infection, they would have reactive antibodies with non reactive NAT. The investigation of these last two cases would require confirmatory tests for antibodies like Western Blot, viral load, if possible by different methods, provirus analysis (integrated DNA) and the determination of the viral subtype by sequenciation..$^{8,9}$

\section{Conclusion}

This case where the serologic screening test for HIV was reactive and the NAT was non reactive in a blood donor was the first one in our institution. This reveals the importance of the use of screening tests for antibodies and antigen P24 for HIV separately or simultaneously and the detection of nucleic acids (NAT) also for HIV in blood donors. The utilization of NAT is essential so as to reduce the window phase but without leaving aside serology tests. Both tests are complementary and not exclusive. This is why, that even when counting on highly sensible techniques for NAT in blood donors, the antibodies' screening must continue.

\section{Acknowledgements}

We thank Dr. Mirta Remesar from Hospital Garrahan, for the performance of Western Blot and viral load assays.

\section{Conflict of interest}

The author declares no conflict of interest.

\section{References}

1. Buenos Aires. Ley 22.990, Ley Nacional de Sangre Decreto Reglamentario $N^{\circ}$ 375/89. Spain: Legislación Vigente; 1983.

2. Documento de Consenso 002-2012. Comité de Infecciones Transmisibles por Transfusión. AAHI. Comité de ITT; 2012.

3. Andrea María Mercedes Mangano. Marcadores genéticos pronósticos en la infección por el HIV-1 Genetic factors in HIV-1 infection. Acta Bioquím Clín Latinoam. 2007;41(4):467-481.

4. Moroni M, Ghezzi S, Baroli P, et al. Spontaneous control of HIV-1 viremia in a subject with protective HLA-B plus HLA-C alleles and HLA-C associated single nucleotide polymorphisms. J Transl Med. $2014 ; 12: 335$

5. Moir S, Chun TW, Fauci AS. Pathogenic mechanisms of HIV disease. Annu Rev Pathol. 2011;6:223-248.

6. Boletín sobre el VIH-SIDA en la Argentina. Año XVII. 2013;30:1-114

7. Buenos Aires. IV Consenso Argentino de Terapia Antirretroviral. Spain: SADI; 2012.

8. Vermeulen M, Coleman C, Mitchel J, et al. Comparison of human immunodeficiency virus assays in window phase and elite controller samples: viral load distribution and implications for transmission risk. Transfusion. 2013;53(10 Pt 2):2384-2398. 